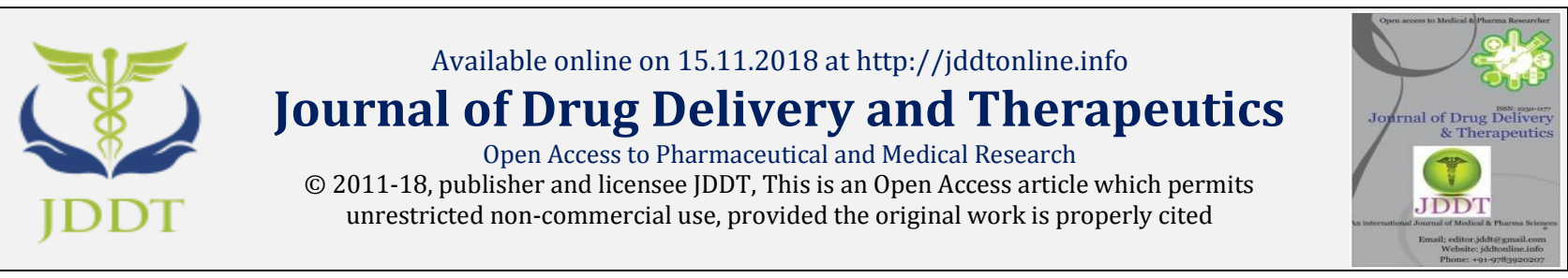

Open $\odot$ Access

Research Article

\title{
Perception on generic drugs among general populace visiting a community pharmacy Jaipur, Rajasthan
}

\author{
Jangra Sarita*, Bhyan Bhupinder, Nair Aprna \\ Department of Pharmacy Practice, Nims Institute of Pharmacy, Nims University Rajasthan, Jaipur-303121
}

\begin{abstract}
Healthcare costs have been leading cause of poverty for many Indians. One of the solutions to this is to advocate generic drugs which are cheaper in comparison to brand name drugs. The government of India had made it mandatory for physicians to use only generic names while prescribing. This study was conducted to analyze the perception of general public in Jaipur, Rajasthan towards generic drugs. A simple close ended questionnaire was administered to selected participants visiting a community pharmacy over a period of 3 months. Patients were asked about their opinions on effectiveness and government promotion of generic substitutions. In the study consisting of 100 participants 92 of them had heard of generic drugs while $76 \%$ knew the difference between generic and branded drugs. $47.8 \%$ believed that brand name drugs were more effective than generic while $34.7 \%$ believed in lower quality of generic drugs. Only $30.4 \%$ of participants were aware of government's efforts to promote generic drugs. $65 \%$ confirmed that they would prefer a generic drug only if it were recommended by a physician and not a pharmacist. Majority of participants had their primary source of information as social media. The result from study suggests that in order to reduce overall healthcare costs of Indians the government must ensure to include all healthcare professionals with physicians as primary informer and also include campaigns through social Medias.
\end{abstract}

Keywords: Healthcare costs, generic drugs, branded drugs, community pharmacy

Article Info: Received 01 Oct, 2018; Review Completed 06 Nov 2018; Accepted 09 Nov 2018; Available online 15 Nov 2018

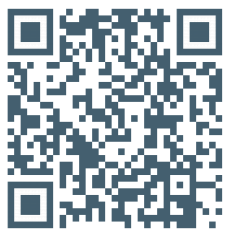

Cite this article as:

Jangra S, Bhyan B, Nair A, Perception on generic drugs among general populace visiting a community pharmacy Jaipur, Rajasthan, Journal of Drug Delivery and Therapeutics. 2018; 8(6):192-194

DOI: http://dx.doi.org/10.22270/jddt.v8i6.2040

Jangra Sarita, Department of Pharmacy Practice, Nims Institute of Pharmacy, Nims University Rajasthan, Jaipur-303121

\section{INTRODUCTION}

Generic medicines are affordable versions of the drug, introduced after the patent acquired by the company over a medicine expires. These medicines are dispensed either by their salt-name or by a brand (called branded generics). However, doctors continue to prescribe branded medicines for various reasons.

India is the largest supplier of generic drugs in the world ${ }^{1}$, and Indian pharmaceutical has helped to reduce healthcare costs of many countries by export of these drugs. Yet, many Indian citizens do not get access to medicines owing to high costs. The National Sample Survey Office (NSSO) survey on healthcare, in 2014, shows that $86 \%$ of the rural population and $82 \%$ of the urban population were not covered under any scheme of health expenditure support, and that medicines are a major component of total health expenses $-72 \%$ in rural areas and $68 \%$ in urban areas 2. Healthcare costs pushed 60 million Indians below the poverty line in 2011. Therefore, even a modest drop in drug prices will free hundreds of households from the widespread phenomenon of a medical poverty. Cheaper medicines are one of the important factors for reducing healthcare $\cos ^{3}$. The Medical Council of India had released a notification on April 2017 making the prescribing of drugs by using their generic names mandatory. The practice of generic substitution is strongly supported by health authorities in many developed countries, where bioequivalence tests are mandatory, to help contain prescription drug spending 4 . These requirements might increase the price of generic medicines slightly, but decrease overall healthcare expenditure. Furthermore they may combat to some extent the distrust of generic medicines by practitioners often due to perceived inferior quality and counterfeiting of drugs 5 .

Exposure to environment or personality and beliefs cause the formation of a perception in an individual. Any action taken by the individual is due to their perception of a particular event. This in influenced by various factors like culture society, economic status and educational status part from each person's individuality. The world health organization has suggested that essential medicines be accessible and affordable to all the public equally. 
This study was conducted to analyze the extend of public perception on generic medicines and to uncover the reasons behind some of them. This would allow researchers and government to take necessary steps and focus on areas needed to improve overall affordability of healthcare in India. Since there is a vast difference in opinion all over India due difference in education levels and upbringing this study was further focused on fining the perception about generic drugs among public in specific area of North India.

\section{MATERIALS AND METHODS}

\subsection{Study Settings and Design}

The primary objective of the study was to analyze the perception of general public about generic drug by comparing their opinion about that of branded drugs. A cross sectional study was conducted on general public visiting a community pharmacy over a period of three months.

\subsection{Study Population and sample size:}

Data from over 100 patients visiting a community pharmacy located in the center of the city was collected. Inclusion criteria were taken as respondents above the age of 20 and economically capable of choosing between generic medicine and branded medicine. Respondents who had not heard of generic medicines and who were below the age of 20 as well as above the age of 80 were excluded as they were not responsible for choosing their preferable medicines.

\subsection{Data Collection Tools}

The responses were categorized to variables as necessary and analyzed using a simple centered close ended questionnaire which was validated among colleagues. It consisted of three parts of which the first part gathered social and educational status of the subjects.

The second part consisted of ten close ended questions which assessed the public's perception on generic medicine, their preferences and conceptions about effectiveness, quality and economic features of generic drugs. Knowledge about government policies regarding the topics was also assessed. Furthermore the role of healthcare professionals were assed as to who the public deemed trustworthy enough to be their primary informer of authentic information about drugs.

A third section consisting of source of information about the drugs and visual aids on general idea about the meaning of generic drugs was also included6. Explanation about the questionnaire and necessary clarification was given to the subjects verbally in vernacular language when necessary.

\section{RESULTS}

Out of the 113 subjects who were requested to participate after taking into consideration inclusion and exclusion criteria, 100 were inducted to answer the questionnaire after proper written consent giving a nonresponder rate of $14.5 \%$. In the present study $40 \%$ of respondents were in age group of $20-29,18 \%$ in age group $30-39,22 \%$ in age group of $40-49,8 \%$ were of age group $50-59,4 \%$ in age group 60-69 and 4\% in age group of 70-79 as shown in Table 1 \& Figure 1

Table 1: Number of the questionnaire respondents in different age groups of Jaipur city $(\mathrm{N}=100)$

\begin{tabular}{|l|c|c|}
\hline S.No & Age Group & Number of Participants \\
\hline 1. & $20-29$ & 40 \\
\hline 2. & $30-39$ & 18 \\
\hline 3. & $40-49$ & 22 \\
\hline 4. & $50-59$ & 8 \\
\hline 5. & $60-69$ & 4 \\
\hline 6. & $70-79$ & 4 \\
\hline
\end{tabular}

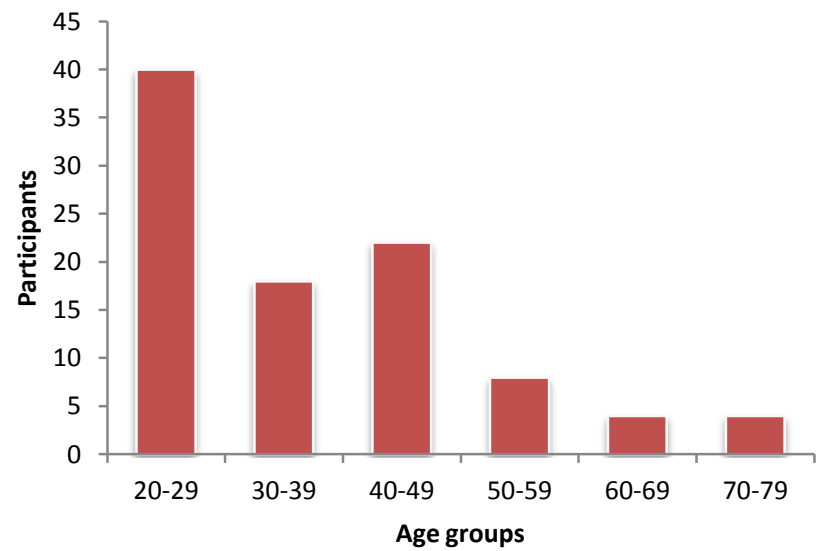

Figure 1: Number of the participants in each age group.

Educational statuses were assessed as high secondary $(12 \%)$, graduate degree $(72 \%)$ or post graduate degree (16\%). Majority of the participants were graduate professionals (72 of 100) as shown in Figure 2

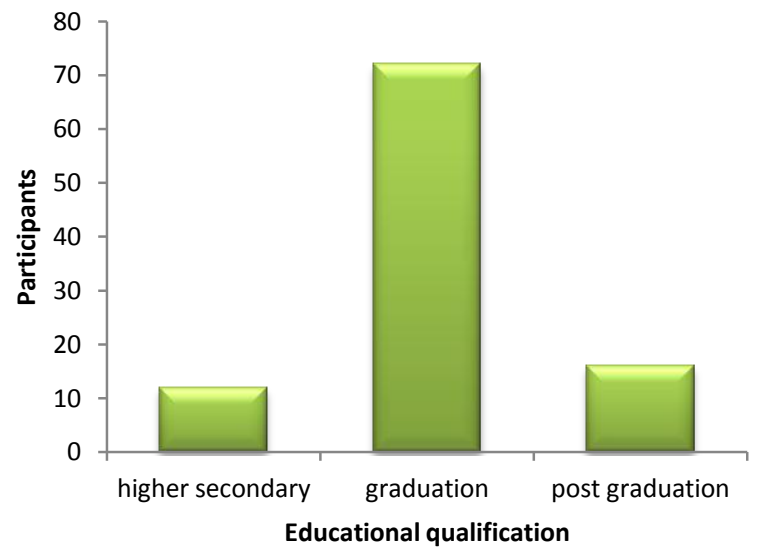

Figure 2: Literacy rate among the participants

$92 \%$ of participants had heard of generic drugs while rest $8 \%$ didn't know about them. Of the 92 participants 70 knew the difference between generic and branded drugs. $14 \%$ of the 92 believed that generic medicines were not cheaper than branded medicines and $50 \%$ preferred to buy 
generic medicines over branded medicines. $47.8 \%$ of them believed that branded medicines are more effective than generic while $34.7 \%$ believed in lower quality of generic medicines. Despite opinions about lower quality and efficacy of generic medicines $84.7 \%$ of participants believed that government should promote generic drugs.

$30.4 \%$ said that they had heard of MCI rule about mandatory prescribing of drugs by their generic name. $88 \%$ said they would readily prefer generic medicines if it were recommended by a healthcare professional (physician or pharmacist) but 35\% said they would not accept a generic substitution given by a pharmacist is shown in figure 3 .

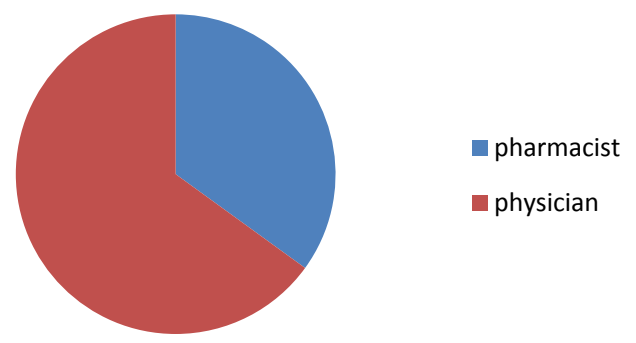

Figure 3: Preferences of participants while accepting a generic drug

With regard to their primary source of information about drugs $8.6 \%$ opted for government agencies and advertisements, $10.8 \%$ from general physician, $8.6 \%$ from pharmacists, $34.7 \%$ from news and social media and $36.9 \%$ from friends and family is shown in figure 4 .

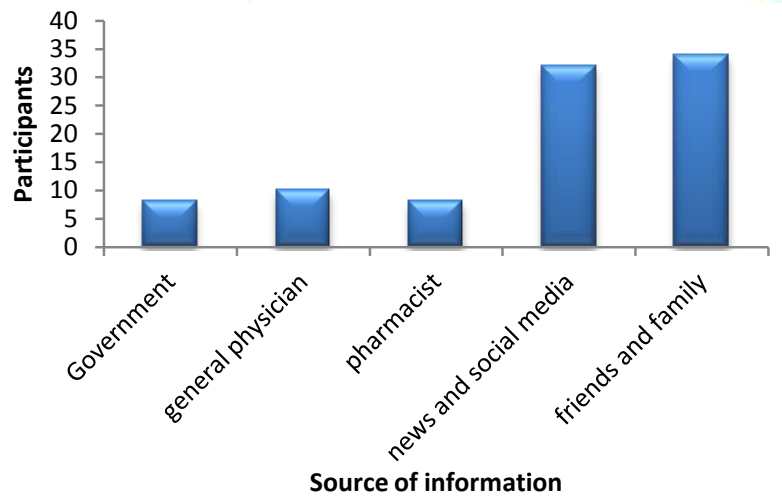

Figure 4: Primary source of information of drugs for participants

The government of India has implemented several policies to ensure affordable healthcare in India by promoting generic drugs. The ministry of health and family welfare had ensured this by implementing mandatory generic drug use in government hospitals in 2012 while MCI had notified that all prescribing be done in generic names.

Though not majority almost half of the participants believed in equal effectiveness (52.2\%) and quality $(65.3 \%)$ of generic and branded drugs. This was similar to a 2008 study conducted in Slovakia where more than half participants $(83 \%)$ believed in equal quality of generic and brand name drugs.

A 2018 study by Tripathi and Bhattacharya in northern India established that $67 \%$ of participants were not aware of government rule about prescribing by generic name ${ }^{7}$. Present study findings have established that doctors are preferred source of generic drug information over the pharmacists. In this study it was found out that $35 \%$ of participants refused to accept a generic drug substitution handed out by pharmacist. This was consistent to a 2009 study conducted in Havard medical school in USA ${ }^{8}$. But primary source of information as indicated by the participants has been news and social media. Despite all this the study received a positive review from the public who were encouraged to look analyze the differences on their own and not just from a single source.

\section{CONCLUSION}

This study shows that though the government has issued various policies for promoting the use of generic medicines the public largely remains ignorant about many facets of healthcare industry regarding generic and brand name drugs. This can rectified only through government campaigns including physicians as public looks to them as an authentic source of information. Roles of pharmacists need also be validated by physician to the public so that the public becomes more accepting to the information shared by them. The government must also ensure that the right information spreads through social media as majority of public seem to depend on them for information. The study also helps in pointing out major misconception among the public about generic medicines and analyses their source of information leading to the conclusion that prescribing of generic drugs by physicians is not enough to tackle challenges faced by healthcare sector in India. Finally study concludes that trust of general population in generic medicine can be establish completely by unanimous efforts of all health care professional, media, government policies.

Acknowledgement: The public who agreed to participate in the study has been acknowledged along with the community pharmacy establishment.

Conflict of interest: The authors declare no conflict of interest.

\section{REFERENCES}

1. Shrank WH, Cadarette SM, Cox E, Fischer MA, Mehta J, Brookhart AM, et al. is there a relationship between patient beliefs or communication about generic drugs and medication utilization? Med Care 2009; 47(3):319-25. doi:10.1097/MLR.0b013e31818af850

2. Stuart VA, Gupta MM, Sealy Patricia, Patients 'Perception of Generic Drugs at Health Institutions in Trinidad and Tobago' J Young Pharm 2017; 9(3):362-366.

3. Al-Gedadi NA, Hassali MA, Shafie AA. A pilot survey on perceptions and knowledge of generic medicines among consumers in Penang, Malaysia. Pharm Pract (Granada). 2008; 6:93-97.

4. Nardi EP, Ferraz MB, Pinheiro GRC, Kowalski SC, Sato EI. Perceptions of the population regarding generic drugs in Brazil: A nationwide survey. BMC Public Health 2015; 15(1):117.

5. Heikkilä R, Mäntyselkä P, Ahonen R. Do people regard cheaper medicines effective? Population survey on public opinion of generic substitution in Finland. Pharmacoepidemiol Drug Saf. 2011; 20(2):185-91.

6. Himmel W, Simmenroth-Nayda A, Niebling W, Ledig T, Jansen $\mathrm{RD}$, Kochen MM, et al. What do primary care patients think about generic drugs? Int J Clin Pharmacol Ther. 2005; 43(10):472-9.

7. Tripathi Shailesh, Bhattacharya Sudeep 'Patient Perception about Generic vs. Branded Medicines Prescribed in a Tertiary Care Hospital in Northern India -A Descriptive Study' Indian journal of pharmacy practice 2011; 2; 91-101.

8. Nelson AA, Gagnon JP. Brand substitution the consumer's viewpoint. J Am Pharm Assoc. 1975; 15(7):382-5. 